\title{
- Right Ventricular Infarction - A Clinical Study
}

\section{Arunkumar S ${ }^{1}$, Sakthivel $\mathbf{V}^{2}$, Babu RP ${ }^{3}$, Jha SJ ${ }^{4}$, Nagarajan P. ${ }^{5}$}

\section{IJCRR}

Section: Healthcare ISI Impact Factor (2019-20): 1.628

IC Value (2019): 90.81 $\operatorname{SJIF}(2020)=7.893$

(c) (7) (3)

Copyright@IJCRR
'Associate Professor, Department of General Medicine, Vinayaga Mission Medical College, Karaikal, Puducherry, lndia; '2Professor, Department of General Medicine, Vinayaga Mission Medical College, Karaikal, Puducherry, India; ${ }^{3}$ Assistant Professor, Department of General Medicine, Vinayaga Mission Medical College, Karaikal, Puducherry, India; 4 Senior Resident, Department of General Medicine, Vinayaga Mission Medical

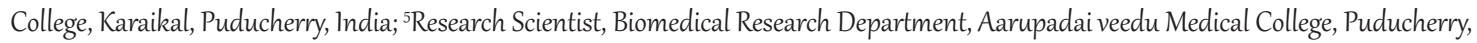
India.

\section{ABSTRACT}

Introduction: Early detection of Right ventricular myocardial infarction is important because the time of onset of its hemodynamic effects is uncertain and the administration of intravenous fluid load can prevent these conditions from occurring.

Aim: To study the occurrence, clinical profile and complication of right ventricular infarction in patients with acute inferior wall myocardial infarction.

Methods: This study included 50 consecutive patients admitted to the Coronary Care Unit or General Medical Unit, Vinayaka Mission Medical College \& Hospital, Karaikal with a proven diagnosis of acute inferior wall infarction.

Results: In 50 patients, 49 patients had chest pain, 43 patients had sweated, 26 patients had vomiting, 8 patients had palpitation, 7 patients had syncope and 4 patients had breathlessness. Based on risk factors, 40 patients had smoking, 21 patients had alcoholism, 19 patients had hypertension, 12 patients had diabetes and 15 patients had dyslipidemia. Dependent on the clinical sign, 9 patients had pallor, 16 had bradycardia, 6 had tachycardia, 16 had hypotension, 16 had elevated JVP, 10 patients had S 3 on the right, and 2 had tender hepatomegaly.

Conclusion: To conclude, the frequency of MI was higher with a prominent symptom in men and age 40 years older and a major risk factor in smoking and a higher mortality in right ventricular infarction patients.

Key Words: Myocardial Infarction, Right ventricular infarction, ECG, Smoking

\section{INTRODUCTION}

The term myocardial infarction is used with ischemia to necrosize the myocardium. It may be subendocardial or transmural. Inferior-wall infarction is associated with some special features, particularly second degree atrioventricular (AV) block and sinus bradycardia, such as the connexion with the right ventricular infarction and bradyarrhythmia.

Right ventricular infarction is different from that of the left ventricle in the acute presentation, therapy and long term prognosis. The early detection of right myocardial ventricular infarction is important as it is unstable at the outset, and can be prevented by intravenous fluid load administration. ${ }^{1}$

Right myocardial ventricular infarction has appeared more than 60 years ago. But it was considered unimportant until Cohn and co-worker in 1974 published their classic report on
Right ventricular myocardial infarction as a distinct clinical entity. ${ }^{2}$

The reporting frequency of myocardial infarction is about 25-50 per cent of the lower wall. ${ }^{3}$ The involvement of RV in the right coronary artery involves significant atherosclerotic occlusion and is linked to the involvement of the posteroinferior wall and the posterior portion of the septum. Clinically correct ventricular myocardial infarction can also be accused of having higher JVP, positive Kussmaul, sign, third or fourth right-side heart rhythms, tender hepatomegaly, oliguria, unusual TR, simple chest in a patient with lower wall myocardial infarction. ${ }^{4}$

Electrocardiogram was considered to be uninformative in the diagnosis of Right ventricular myocardial infarction before Erhardt and co-workers explained the significance of Right Precordial Lead in patients with autopsy reported Right Ventricular Myocardial infarction. The $1 \mathrm{~mm}$ ST elevation of

\section{Corresponding Author:}

Arunkumar S, No 239, Church Street, Karaikal - 609602

Phone: 9790029192; Email: avsarun.kkl@gmail.com

ISSN: 2231-2196 (Print)

ISSN: 0975-5241 (Online)

Received: 12.11 .2020

Revised: 08.01 .2021

Accepted: 15.03 .2021

Published: 05.07 .2021 
this lead is 70 per cent adaptive and 100 per cent specific. A shift is temporary. In one series, 48 per cent of patients had ECG resolution improvements within 10 hours of initiation of symptoms. ${ }^{2}$

Bradycardia is the most prevalent arrhythmias during the early stage of acute myocardial infarctions and is more common in patients with both lower and postoperative infarctions, inferior myocardial wall myocardial violation can cause all forms of AV conduction disruptions and intraventricular blocks more frequently than AWMI. In both, the 2nd degree AV block Mobitz Type 1 arises normally in the lower wall inferior to the anterior wall infarction myocardial. Usually, this is reversible and will not last longer than 72 hours after infarction. ${ }^{5}$

\begin{abstract}
AIM
To study the occurrence, clinical profile and complication of right ventricular infarction in patients with acute inferior wall myocardial infarction.
\end{abstract}

\section{MATERIALS AND METHODS}

A total of 50 patients were included in this study, with an existing diagnosis of acute inferior wall myocardial infarction from 2008 to 2009, in the Coronary Care Unit or General Medical Unit Vinayaka Medical College and the Karaikal. Institutional ethical committee approval was obtained. (ECR No: ECR/1147/INST/PY/2018)

Inclusion criteria: Patients admitted or diagnosed with acute inferior wall myocardial infarction were included.

Exclusion criteria: Patients with a known history of Chronic Lung Disease, Previous MI, Rheumatic Heart Disease and Pericardial Disease or LBBB were excluded. Patients, presented after $24 \mathrm{hrs}$ of the onset of chest pain were excluded as the ST changes in right ventricular infarction may be transient.

Patients underwent 12 leads ECG and were examined at the time of admission, second day and up to the day of discharge. Only those cases with hyperacute inferior wall infarction were included in the study. Patients with slope elevation of ST-segment in leads II, III and aVF were taken as having hyperacute inferior wall infarction.

All patients were assessed clinically and electrocardiographically with special emphasis on presenting complaints, risk factors, vital signs, arrhythmias and mortality. Data were collected using proforma and presented as frequency and percentage.

\section{RESULTS}

41 patients were male and 9 were female out of 50 patients. Owing to the high prevalence of the age group, two classes have been identified. The first group is 42 years old and the second group is 62 years old. The youngest age was 33 , the oldest age 80 ( Table 1).

\begin{tabular}{|c|c|c|c|}
\hline Age & Total No. of patients & Male & Female \\
\hline $30-34$ & 1 & 1 & o \\
\hline $35-39$ & 1 & 1 & $\mathrm{o}$ \\
\hline $40-44$ & 10 & 9 & 1 \\
\hline $45-49$ & 7 & 7 & o \\
\hline $50-54$ & 3 & 3 & o \\
\hline $55-59$ & 8 & 7 & 1 \\
\hline $6 o-64$ & 10 & 7 & 3 \\
\hline $65-69$ & 4 & 7 & 1 \\
\hline $70-74$ & 4 & 2 & 2 \\
\hline $75-79$ & 1 & 1 & o \\
\hline 80 and & 1 & o & 1 \\
\hline Total & 50 & 41 & 9 \\
\hline
\end{tabular}

Out of 50 patients, 49 patients had chest pain, 43 patients had sweated, 26 patients had vomiting, 8 patients had palpitation, 7 patients had syncope, 4 patients had breathlessness ( Table 2).

Table 2: Presenting Symptoms.

\begin{tabular}{lcc} 
Symptoms & No. of Patients & Percentage \\
Chest Pain & 49 & 98 \\
Sweating & 43 & 86 \\
Vomiting & 26 & 52 \\
Palpitation & 8 & 16 \\
Syncope & 7 & 14 \\
Breathlessness & 4 & 8 \\
\hline
\end{tabular}

Out of 50 patients, 40 patients had smoking, 21 patients had alcoholism, 19 patients had hypertension, 12 patients had diabetes, 15 patients had dyslipidemia.

Radiation to the left upper limb was noticed in 19 (38\%) of patients, $3(6 \%)$ patients had radiation to the right upper limb. Another 3 patients $(6 \%)$ had radiation to the epigastrium (Table 3). 
Table 3: Risk Factors.

\begin{tabular}{lcc} 
Risk factors & No.of patients & Percentage (\%) \\
Smoking & 40 & $80 \%$ \\
Alcohol & 21 & $42 \%$ \\
Systemic Hypertension & 19 & $38 \%$ \\
Diabetes Mellitus & 12 & $24 \%$ \\
Dyslipidemia & 15 & $30 \%$ \\
\hline
\end{tabular}

Out of 50 patients, 9 patients had pallor, 16 had bradycardia, 6 had tachycardia, 16 had hypotension, 16 had elevated JVP, 10 patients had $\mathrm{S}_{3}$ in the right side and 2 had tender hepatomegaly ( Table 4).

Table 4: Clinical signs at the time of Presentation

\begin{tabular}{lcc} 
Clinical Signs & No.of patients & Percentage (\%) \\
Pallor & 9 & $18 \%$ \\
Pulse $<60 / \mathrm{min}$ & 16 & $32 \%$ \\
Pulse $>100 / \mathrm{min}$ & 6 & $12 \%$ \\
$\mathrm{BP}<100 \mathrm{~mm} \mathrm{Hg}$ systolic & 16 & $32 \%$ \\
Elevated JVP & 16 & $32 \%$ \\
Right sided S3/S4 & 10 & $20 \%$ \\
Tender Hepatomegaly & 2 & $4 \%$ \\
\hline
\end{tabular}

ECG and clinical criteria for right ventricular infarction were present in $20(40 \%)$ patients. True posterior wall infarction as evidence by $\mathrm{R} / \mathrm{S}$ ratio $>1$ in $\mathrm{V} 1$ with upright $\mathrm{T}$ wave was observed in $9(18 \%)$ patients. In all these patients the typical change was evident only after 24 hours.

First degree AV block was observed in 5 ( $10 \%)$ patients. Second degree - mobitz type I block was seen in $3(6 \%)$ patients. Second degree - mobitz type II block was present in $1(2 \%)$ patient.

Complete heart block was noted in $6(12 \%)$ patients. Transient complete right bundle branch block (RBBB) was noted in 14 cases (28\%) Left anterior hemiblock was present in 2 cases (4\%). Atrial fibrillation was present in 7 (14\%) patients and it developed within the first 24 hours. Sinus bradycardia was present in $5(10 \%)$ patients and ventricular premature complexes were present in $5(10 \%)$ patients. Papillary muscle dysfunction and mitral regurgitation were noted in 2 (4\%) patients. Out of the 7 patients who expired in the hospital, 6 of them passed away within 48 hours of admission. These patients had got right ventricular infarction, profound hypotension, complete heart block and arrhythmias. The remaining one patient developed a cerebrovascular accident ( right-sided hemiplegia) CT scan showing infarct in the left middle cerebral artery territory (Table 5).
Table 5: Complications developed during follow up.

\begin{tabular}{lcc} 
Complications & No. of patients & Percentage (\%) \\
Atrial Fibrillation & 7 & 14 \\
I Heart Block & 5 & 10 \\
II Heart Block & 0 & 0 \\
Mobitz type I & 3 & 6 \\
Mobitz type II & 1 & 2 \\
Complete heart block & 6 & 12 \\
RBBB & 12 & 28 \\
LAHB & 2 & 4 \\
VPC's & 5 & 10 \\
Sinus Bradycardia & 5 & 10 \\
Papillary muscle dys- & 2 & 4 \\
function & & 4 \\
Mitral regurgitation & 2 & 14 \\
Mortality & 7 & \\
\hline
\end{tabular}

\section{DISCUSSION}

Twenty proven cases of Acute Inferior Wall Myocardial Infarction were selected in the study to examine risk factors associated and to find out how many cases of Inferior Wall Myocardial Infarction are involved in right ventricular myocardial infarction and to evaluate the complications and outcomes of patients. When it was analysed, the Acute Lower Wall Myocardium Infarction was observed to be more frequent above the age of 40 years. $96 \%$ of patients met 40 , $83.3 \%$ of whom were male. In Right ventricular myocardial infarction after inferior wall myocardial infarction, Chang et al. ${ }^{6} 1992$ find sex distribution.

98 per cent of patients had chest pain. They all had common retrosternal chest pain lasting longer than 30 minutes. When evaluating symptoms other than chest pain, the most common was sweating in 86 per cent of patients. It has also been correlated with cold extremities and pallor.

Pallor was noted in 18 per cent of patients on the analysis of clinical features. Bradycardia was reported in 28 per cent of patients. Of these, 60 per cent had a conduction disturbance and the remaining 40 per cent had an associated Right Ventricular Infarction. About the previous study, only $34 \%$ of patients had systolic BP less than $100 \mathrm{~mm} / \mathrm{Hg}$ at the time of presentation. Of these 14 patients $(28 \%)$ had right ventricular infarction. ${ }^{7}$

Harrison et al. Kussmaul positive sign results range from (10\%-90\%) in Right Ventricular Myocardial infarction. ${ }^{8}$

Smoking was the most frequent risk factor followed by alcohol, hypertension, dyslipidemia and diabetes when analysing the coronary disease risk factor. Blackwell et al. smoking and type 2 diabetes increased the occurrence of Right Ven- 
tricular Myocardial Infarction (74\%). ${ }^{9}$

In our sample, RBBB complication accompanied by atrial fibrillation, death, and full heart obstruction, etc. In 1950 Bakos identified RBBB and full heart block are the most prominent conduction anomalies associated with Right Ventricular Myocardial infarction. ${ }^{10}$ The recorded frequency of atrial fibrillation in Acute Myocardial Infarction is 10-15\%, but only $1 / 3$ of those with Inferior was MI relative to Anterior Wall MI. ${ }^{11}$ Buenoh et al. ${ }^{12}$ recorded 90 per cent cardiogenic shock interaction in his research of those with Right Ventricular Myocardial infarction. Most death in Right Ventricular Myocardial infarction is attributable to cardiogenic shock and conduction abnormalities. ${ }^{13}$ Chockalingam et al. ${ }^{14}$ recorded $16 \%$ mortality in their study of Right Ventricular Myocardial infarction patients.

\section{CONCLUSION}

To conclude, the frequency of myocardial infarction was higher with a prominent symptom in men and age 40 years older and a major risk factor in smoking and higher mortality in right ventricular infarction patients. Almost all patients had typical retrosternal chest pain lasting more than 3 minutes associated with sweating. Syncope was a prominent symptom in patients with right ventricular infarction. Mortality is higher in a patient with Right ventricular Myocardial infarction when compared with those without this complication.

\section{ACKNOWLEDGEMENT}

Authors acknowledge the immense help received from the scholars whose articles are cited and included in references to this manuscript

\section{Conflict of interest: Nil}

Financial support: No

\section{REFERENCES}

1. Braunwald E, Zipes DP, Libby P, Bonow R. Braunwald's heart disease: a textbook of cardiovascular medicine, single volume. Saunders, 7 Edition. 2004.

2. Cohn JN. Right ventricular infarction revisited. Am J Cardiol. 1979;43:666.

3. Mittal SR. Isolated right ventricular infarction. Int $J$ Cardiol. 1994 Aug. 46(1):53-60.

4. Mann JM, Roberts WC. Rupture of the left ventricular free wall during acute myocardial infarction: analysis of 138 necropsy patients and comparison with 50 necropsy patients with acute myocardial infarction without rupture. Am J Card. 1988 Nov 1;62(13):847-59.

5. Rotman M, Wagner GS, Wallace AG. Bradyarrhythmias in acute myocardial infarction. Circulation. 1972 Mar;45(3):703-22.

6. Hammar N, Nerbrand C, Ahlmark G, Tibblin G, Tsipogianni A, Johansson S, Wilhelmsen L, Jacobsson S, Hansen O. Identification of cases of myocardial infarction: hospital discharge data and mortality data compared to myocardial infarction community registers. Int J Epidemiol. 1991 Mar 1;20(1):114-20.

7. Berger PB, Ryan TJ. Inferior myocardial infarction. High-risk subgroups. Circulation. 1990 Feb;81(2):401-11.

8. Edwin L. Bierrman; Harrison's principles of Internal Medicine, 13th End. P. 1108.

9. Smith C, SAULS HC, Ballew J. Coronary occlusion; a clinical study of 100 patients. Ann Intern Med. 1942 Oct 1;17(4):681-92.

10. Bakos AC. The question of the function of the right ventricular myocardium: an experimental study. Circulation. 1950 Apr;1(4):724-32.

11. James TN. Myocardial infarction and atrial arrhythmias. Circulation. 1961 Oct;24(4):761-76.

12. Bueno H, López-Palop R, Bermejo J, López-Sendón JL, Delcán JL. The in-hospital outcome of elderly patients with acute inferior myocardial infarction and right ventricular involvement. Circulation. 1997 Jul 15;96(2):436-41.

13. López-Sendón J, de Sá EL, Maqueda IG, Coma-Canella I, Ramos F, Domínguez F et al. Right ventricular infarction as a risk factor for ventricular fibrillation during pulmonary artery catheterization using Swan-Ganz catheters. Am Heart J. 1990 Jan 1;119(1):207-9.

14. Chockalingam A, Gnanavelu G, Subramaniam T, Dorairajan S, Chockalingam V. Right ventricular myocardial infarction: presentation and acute outcomes. Int Angiol. 2005 Jul;56(4):371-6. 